\title{
PERBANDINGAN PERIBAHASA BAHASA INDONESIA DAN BAHASA INGGRIS: KAJIAN SEMANTIK KOGNITIF
}

\author{
Muhammad Hafiz Kurniawan. Universitas Ahmad Dahlan. \\ muhammad.kurniawan@enlitera.uad.ac.id
}

\begin{abstract}
Language is the medium to communicate among human beings and this is in accordance to two language functions namely expressive and social function which cannot be separated. Those two functions lead to the variation of language use. One of those variations of language use is proverbs to express specific meaning in daily conversation. Proverb is also considered the language artifact because it can show the culture of language users. Therefore, this research has an aim to compare two proverbs from Bahasa Indonesia and English to analyze the expressions used in those two languages so that the cultural characteristics of English and Bahasa Indonesia could be revealed. The data of this research were taken from Oxford dictionary and book containing Bahasa Indonesia proverbs. This research uses the prismatic model developed by Geeraerts which is then simplified to analyze the metaphor of the proverbs. The result of this research shows that the proverbs between those two langauges reveal the culture of the language users from the aspects used in those proverbs.
\end{abstract}

Keywords: Proverbs, Metaphor, Cognitive Semantics

\section{PENDAHULUAN}

Bahasa merupakan sebuah media untuk berkomunikasi antara satu individu dengan individu lainnya .Hal tersebut sesuai dengan fungsi bahasa yang ketiga dan keempat yang tidak bisa dipisahkan yaitu fungsi ekspresif dan fungsi sosial (Lyon, 1977, 51).Fungsi ekspresif dan sosial ini kemudian memunculkan keragaman bentuk penggunabahasa karena fungsi ekspresif dan sosial ini (Ibid, 1977: 51).Meskipun demikian, keragaman penggunaan bahasa karena pengaruh ekspresif dan sosial ini tetap saja mengacu pada suatu konsep yang sama. Dengan kata lain, suatu konsep yang ada di pikiran manusia dapat disampaikan dengan cara yang berbeda dan beragam.

Keterkaitan antara konsep dan bahasa ini telah lama diutarakan oleh Saussure dalam bukunya Course de Linguistic Generale yang dianggap sebagai terobosan baru dalam ilmu linguistik yang mengubah corak linguistik yang semula diakronik menjadi sinkronik. Saussure dalam bukunya tersebut membedakan antara sign, signified, dan signifier yang merupakan suatu konsep untuk menjelaskan mengenai bahasa bahwa bahasa itu tersusun atas tiga hal tersebut. Saussure berpendapat bahwa sign merupakan keseluruhan dari makna suatu bahasa, sedangkan signified merupakan konsep yang menggambarkan suatu benda atau objek, sedangkan signifier merupakan bahasa yang diujarkan atau digunakan yang sifatnya manasuka atau arbitrer (1959: 66-67).

Saussure memberikan contoh misalnya kata 'arbor' kata ini bagi seseorang yang tidak mengetahui bahasa Latin akan sulit menerka apa yang dimaksud dengan kata tersebut, karena sifat bahasa adalah arbitrer atau manasuka. Kata 'arbor' ini merupakan bahasa sehingga dinamakan sebagai sound image atau signifier 
sedangkan pohon (maksudnya gambar pohon) adalah konsep itu sendiri atau signified sedangkan sign merupakan gabungan dari signified dan signifier. Sehingga jika seseorang tidak bisa memahami salah satu dari kedua hal tersebut yaitu signifier ataupun signified maka komunikasi tak akan berjalan dengan baik.

Pandangan itu merupakan gambaran akan konsep bahasa secara struktural. Namun, bahasa dalam berkomunikasi tidak hanya terkait dengan dua hal itu dalam prakteknya karena terkadang dan bahkan seringkali terjadi satu signifier bisa mewakili dua atau lebih signified, sehingga tidaklah mengherankan jika seorang filusuf, Ludwig Wittgenstein, mengibaratkan bahwa bahasa seperti sebuah permainan. Dia mengibaratkan bahasa dengan gambar orang tersenyum. Seseorang akan beranggapan bahwa orang yang sedang tersenyum itu baik dan ramah namun dalam keadaan tertentu senyuman itu bisa berarti kejam (Wittgenstein, 1958: 539). Maksud dari ramah dan kejam sesuai dengan kondisi adalah ketika orang tersebut senyum kepada orang lain yang tengah berbahagia dan tertawa maka orang itu bisa dikatakan ramah, namun jika orang tersebut tersenyum ketika melihat orang sedang menderita maka orang tersebut bisa dianggap kejam.

Kenyataan bahwa bahasa tidak hanya dilihat dalam hal strukturalnya saja juga diakui oleh Saussure sendiri dalam bukunya bahwa adanya elemen ekternal bahasa bisa mempengaruhi bahasa sebagaimana yang disampaikan oleh Saussure bahwa "the culture of the nation exerts an influence on its language...(Saussure, 1959: 20)”. Budaya secara tidak langsung mempengaruhi penggunaan bahasa penuturnya karena sebagaiman yang dikatakan oleh Boas dalam Ahern bahwasannya"the particular language spoken by a group of people merely tended to reflect their habitual practices" (Ahern, 2012: 67).Hal ini didasari pada kenyataan bahwa seseorang berbicara akan menggunakan benda-benda atau apapun yang ada di dekatnya, paling tidak membicarakan sesuatu yang pernah dilihatnya. Seseorang bisa mengatakan dan menjelaskan mengenai Tembok Besar China atau The Great Wall karena dia mungkin pernah berkunjung ke sana atau paling tidak melihat Tembok Besar China itu di acara-acara televisi atau pernah membacanya di buku. Sehingga ada suatu hipotesis yang diajukan oleh Sapir dan Whorf mengenai hubungan antara bahasa, budaya, dan pikiran.

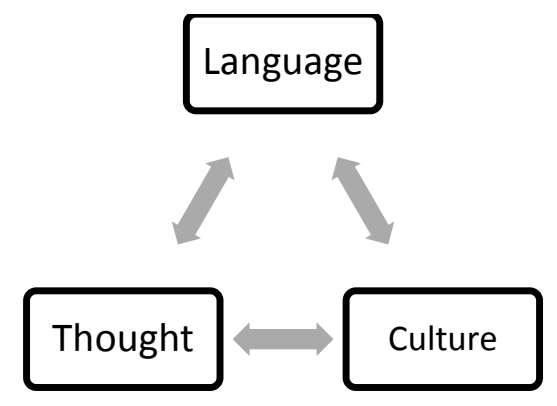

Gambar 1. Hipotesis Sapir dan Whorf (Sumber: Ahern, 2012: 70)

Pengaruh bahasa dan budaya bisa dilihat dalam berbagai hal sebagaimana yang dinyatakan oleh Foley bahwa peribahasa atau proverb merupakan contoh yang luar biasa untuk menggambarkan hubungan antara budaya, bahasa dan pikiran, sebagimana yang ia katakan bahwa:

"Our mouths are full of the words of others, which we apply to our present circumstances. A superb example is the proverb. Proverbs are passed on generation to generation in a quite fixed form to communicate an important moral and practical truth which pertains to a new situation. There are words of others, recontextualization in our present now, in order to provide an interesting or important viewpoint on the present situation. They derive their power both 
from their formal fixed rather poetic structure and from their carrying a kind of folksy received wisdom, a putatively widely shared public opinion" (Foley, 1997: 361).

Dari penjelasan di atas jelas dikatakan bahwa dalam peribahasa tercermin suatu kearifan lokal atau folksy wisdom yang mengandung suatu moral atau kebenaran yang menjadi nilai-nilai yang dianut oleh suatu masyarakat.Menurut Soebok (1962) melalui Foley bahwasannya "Genre like proverbs, charms, and spells and some types of poetry have highly stereotypical and constrained form...(Ibid, 1997: 361-362). "Proverbs atau peribahasa bentuknya lebih cenderung menampakkan budaya dari suatu bangsa karena proverbs merupakan bahasa yang diturunkan dari generasi ke generasi.

Bahasa peribahasa bukanlah bahasa yang literal yang langsung mengarah ke pesan moral yang ingin disampaikan, namun lebih pada bahasa yang iliteral atau tersirat. Bahasa kias atau figurative languageinilah yang menjadi menarik, bahkan menarik untuk para antropolog, linguis, dan filusuf. Sebagaimana yang dikatakan oleh Duranti bahwa para antropolg, linguis, dan filusuf tertarik pada "..how the specific form and content of our speech can be seen as our guide to our experience of the world" (Duranti, 1997: 38) atau bagaimana bentuk-bentuk spesifik dan isi dari percakapan bias menuntun pada pengalaman seseorang pada dunia.

Bahasa kias yang dimaksud adalah metafora sebagaimana yang dikatakan oleh Rosch (1973, 1978) melalui Duranti bahwsannya kajian kognitif metafora sebagai skemata budaya terkait erat dengan gagasan yang orang-orang pahami mengenai dunia, dalam hal prototype, yang disederhanakan atau pandangan yang digeneralisasikan atau teori pengalaman bangsa
(Ibid). Meskipun bahasa kias itu berbeda-beda penggunaannya, namun ada suatu kesamaan dalam maknanya. Hal ini didasari pada pemikiran strukturalisme Levi-Strauss bahwa pemikiran manusia semuanya sama dan budayabudaya itulah yang menyebabkan perbedaan dalam pemikiran tersebut yang diadaptasikan dengan kondisi lingkungan hidup tertentu (Ibid, 1997: 33). Dasar pemikiran Levi-Strauss inilah yang menjadi dasar penulisan perbandingan peribahasa Inggris dan peribahasa Indonesia, dengan asumsi bahwa meskipun bahasa dan referennya berbeda namun inti atau makna yang dimaksud sama. Pemikiran Levi-Strauss ini sebenarnya diinspirasi oleh pemikiran Chomsky dan Jakobson sebagaimana yang dikatakan oleh Pettit melalui Ahimsa-Putra yaitu "to look for something like Chomsky's grammar or Jakobson's phonology" (Ahimsa-Putra, 2013: 32).

\section{a. Penelitian Terdahulu}

Penelitian terdahulu yang telah membahasa mengenai perbandingan peribahasa adalah penelitian dari Mirahayuni dan Garnida (2016) yang berusaha menjelaskan peribahasa Inggris yang menggunakan unsur kuda serta menemukan padanannya dalam bahasa Indonesia. Beberapa peribahasa Inggris yang menggunakan kata kuda juga memiliki padanan yang sama dalam bahasa Indonesia, yaitu menggunakan kata kuda juga. Meskipun demikian, beberapa peribahasa tidak memiliki padanan yang sama. Fokus utama dalam penelitian mereka adalah menelaah nilainilai yang terkandung di dalam peribahasa bahasa Inggris dan mencari padanannya dalam bahasa Indonesia.

Penelitian yang kedua adalah penelitian tentang mencari padanan peribahasa Indonesia 
dengan peribahasa Jepang dengan menggunakan kata "anjing" telah dilakukan oleh Hanindar dan Andini (2017).Dalam penelitian tersebut, kata anjing yang digunakan dalam peribahasa Jepang dicari padanannya dalam bahasa Indoensia yang tidak semua memiliki kesamaan dalam penggunaan kata hewan.Analisis tersebut menitikberatkan pada analisis makna denotasi dan kontasinya.

Penelitian ketiga adalah tentang tentang suatu kajian nilai budaya peribahasa Jepang dan Indonesia yang menggunakan unsur nama binatang yang telah dilakukan oleh Hadi dan Nurhadi (2018). Peneltian tersebut membandingkan frekuensi pemakaian namanama hewan dalam menyatakan suatu nilai-nilai budaya. Perbandingan tersebut dimaksudkan untuk menelaah tentang tiga hal yaitu nama hewan yang digunakan dan makna yang dinyatakan sama, nama binatang yang digunakan sama namun memiliki makna yang berbeda dan nama binatang yang digunakan sama namun makna saling bertolak belakang. Selain itu, penelitian ini juga menganalisis nilai-nilai budaya yang ada di kedua peribahasa tersebut.

Penelitian ini memiliki persamaan dan perbedaan dengan penelitian terdahulu. Persamaan penelitian ini dengan penilitian yang terdahulu adalah penelitian ini menganalisis peribahasa Inggris dan padanannnya dalam bahasa Indonesia dengan mengabaikan kesamaan unsur yang diguanakan dalam peribahasa tersebut. Perbedaan unsur yang digunakan akan menunjukkan perbedaan budaya dari kedua pengguna bahasa tersebut. Perbedaan penelitian ini dengan penelitian sebelumnya adalah penelitian ini menggunakan metafora dan model prisma yang dikembangkan oleh Geeraerts dalam menganalisis peribahasa.

\section{b. Metode Pengumpulan Data dan Analisis Data}

Metode pengumpulan data yang digunakan dalam makalah ini, karena keterbatasan waktu, menggunakan teks tertulis sebagai data.Menurut Ahearn ada beberapa metode dalam pengumpulan data pada penelitian etnolinguistik yang tujuannya adalah untuk mengumpulkan informasi mengenai penggunaan bahasa dalam konteks sosial yang aktual (Ahern, 2012: 35). Beberapa penelitian tersebut meliputi, observasi partisipan, wawancara, survey dan kuosioner, percakapan natural, metode eksperimen, tes kecocokan, dan teks tertulis (Ibid: 35-41). Makalah ini menggunakan data tertulis berupa peribahasa yang tercantum dalam buku peribahasa Indonesia (Chaniago dan Pratama, 1998)dan dalam kamus Oxford untuk peribahasa Inggris (2005).Sehingga data yang digunakan dalam penelitian adalah data tertulis (Moleong, 2015: 159)

Metode analisis data dalam makalah ini menggunakan metode penelitian kontrastif, yaitu metode penelitian yang membandingkan bahasa yang satu dengan bahasa yang lainnya, dalam hal ini peribahasa Indonesia dan peribahasa Inggris.Metode kontrastif ini bisa dilakukan pada penelitian etnolinguistik sebagaimana yang disampaikan oleh Poedjosoedarmo bahwa penelitian ini diawali dengan membandingkan bahasa-bahasa tersebut untuk memperoleh gambaran mana yang dianggap penting pada bahasa satu dan mana yang dianggap penting pada bahasa yang lain, dan agar penelitian itu lebih mendalam maka harus didukung dengan sudut pandang lain yaitu dengan sudut pandang antropologi (Poedjosoedarmo, 1983: 63). 


\section{c. Problematika}

Permasalahan yang diangkat dalam makalah yang menggunakan metode kontrastif analisis ini adalah (1) referen yang digunakan dalam peribahasa Indonesia dan peribahasa Inggris mengenai satu hal yang memiliki makna atau nilai moral yang sama pada keduanya, (2) alasan penggunaan referen-referen tersebut untuk membangun suatu makna dalam peribahasa Inggris dan Indonesia. Problematika yang pertama yaitu mengenai referen yang digunakan dalam peribahasa Indonesia dan peribahasa Inggris dengan teori metafora. Problematika yang kedua setelah mengetahui referen-referen yang digunakan yang tercermin dalam leksikon yang dipakai dalam metafora maka akan dianalisis alasan pemakaian leksikon tersebut dengan budaya.

\section{d. Dasar Teori}

Teori yang digunakan dalam makalah ini adalah teori metafora.Pengambilan teori metafora ini didasari pada pendapat Duranti bahwa "metaphors as folk theories of the world" atau metafora sebagai teori bangsa di dunia.Metafora menurut Duranti dianggap sebagai suatu media untuk mentransfer budaya melalui bahasa kemudian melalui komunikasi (Duranti, 1997: 38). Metafora juga disebut juga sebagai sebuah alat dalam menganalisis proverb atau peribahasa (Langlotz, 2006: 44).Selain itu kenyataan yang terjadi adalah bahwa manusia tak pernah berbicara dari suatu kekosongan semua yang dibicarakan oleh manusia berdasarkan pada apa yang dilihatnya dan apa yang dikenalnya. Kenyataan telah dirumuskan oleh Lakoff dan Johnson melalui Foley bahwa sumber dari pembicaraan itu terpusat dari pengalaman, dan Foley menambahkan bahwa:
"Human understanding of any target domain is structured first and foremost in terms of the human body and its everyday practical interaction with the physical world; this is the pre-eminent source domain of metaphor (Foley, 1997: 183)"

Sumber dari domain atau referen metafor menurut Foley dan Lakoff dan Johnson bersumber dari sesuatu yang berada di sekitar diri manusia, baik itu tubuh manusia itu sendiri, lingkungan tempat tinggal, yang keseluruhannya menjadi suatu kesatuan dalaminteraksi antara manusia dengan dunia fisik.Metafora merupakan salah satu dari bahasa kias yang oleh Tarigan digolongkan sebagai gaya bahasa perbandingan. Menurut Dale et al melalui Tarigan metafora berasal dari bahasa Yunani yaitu meta dan pherein yang masing-masingnya bermakna melebihi dan membawa yang secara keseluruhan bermakna memindahkan (Tarigan, 1985: 15).

Kata memindahkan ini senada dengan pendapat Foley bahwa dalam penggunaan metafora ada fitur-fitur dari source of domain ke sesuatu yang dibandingkan. Foley memberi contoh "Ed is a jellyfish". Jellyfish atau uburubur ini merupakan hewan tak bertulang belakang yang lembek, fitur ini diambil untuk menggambarkan sifat Ed, sehingga bisa diartikan bahwa Ed merupakan orang yang lemah, tak mempunyai kekuatan sebab tulang belakang merupakan simbol dari kekuatan dan keteguhan (Foley, 1997: 182-183). Dan Quinn melalui Foley mengatakan bahwa the choice of metaphors for some domains is not totally random, but reflects some basic cultural understandings individuals have of that domain (Ibid, 1997: 183).

Konsep utama metafora adalah membandingkan antara A dan B yang diasumsikan memiliki kesamaaan sifat atau lebih tepat sifatnya disamakan. Konsep ini kemudian 
dikenal dalam conceptual metaphor yang mengenalkan dua konsep yaitu konsep source domain dan target domain. Target domainadalah domain yang akan dicoba untuk dimengerti melalui penggunaan source domain. Hal-hal seperti, misalnya dalam bahasa Inggris, 'life', 'arguments', 'love', 'theory', 'ideas', 'social organizations' adalah target domain sedangkan 'journey', 'war', 'building', 'food', 'plants' adalah source domain (Kovesces, 2010: 4). Jadi jika ada suatu peribahasa dalam bahasa Inggris time is money maka target domainnya adalah time sedangkan source domain-nya adalah money. Setelah mengetahui source domain dan target domain maka perlu untuk mengetehaui fitur apa yang ada pada source domain yang akan diberikan kepada target domain sehingga terbentuklah suatu makna yang utuh dari metafora tersebut.

Fitur yang diambil dari source domain bisa dipahami dengan melihat sifat-sifat dari source domain yang terdapat pada setiap pemikiran manusia, sehingga perlu menghadirkan domain yang ketiga yaitu thought domain atau domain pikiran. Tiga jenis domain ini mengacu pada segitiga semiotik Ogden dan Richard (1923: 11). Jika dalam Ogden dan Richard terdapat A, B, C yang masing-masing mengacu pada pemikiran, simbol, dan referen, maka dalam teori metafora ini dengan mengacu pada teori conceptual metaphor, akan mengadopsi konsep segitiga semiotik untuk melihat maknanya secara keseluruhan. Meskipun konsep yang diangkat oleh Ogden dan Richard dan konsep yang diangkat dalam teori ini sedikit berbeda namun dengan mengadopsi konsep segitiga semiotik maka akan terlihat jelas hubungan antara source domain, target domain dan (thought domain).
Maka konsep tersebut dapaat digambarkan sebagai berikut:

\section{A (Concept)}
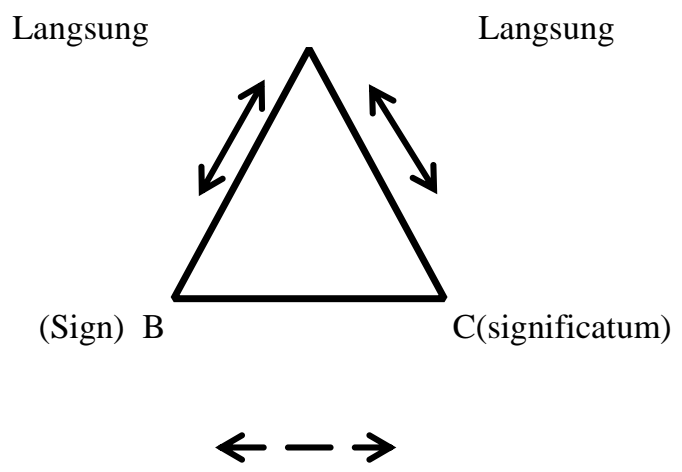

Tak langsung

Gambar 2. Segitiga Makna (sumber: Lyon, 1977: 96)

Dengan mengadopsi segitiga semiotik Ogden dan Richard maka akan terjadi suatu pemahaman bahwa source dan target akan dihubungkan secara langsung oleh pemikiran dan pikiran akan sesuatu hal dalam metafora peribahasa ini. Meskipun berbeda dalam hal source dan target, ada kesamaan yang terjadi yaitu pada thought atau pemikiran yang menurut Levi-Strauss sama pada semua orang dan yang membedakannya adalah konstruksi budaya yang dipengaruhi oleh keadaan di sekitar manusia (Foley, 1997: 33).

Dalam penelitian kontrastif analisis yang sederhana ini akandisesuaikan dengan problematika yang diangkat dalam penelitian ini. Pertama kali yang dilakukan adalah menganalisis data yang berupa dua peribahasa Indonesia dan peribahasa Inggris yang memiliki arti yang sama, kemudian dicari perbedaan antara source domain dan target domain dan analisis yang kedua adalah mencari alasan kenapa source domain dan target domain tersebut berbeda. Sudut pandang 
budaya akan dicoba untuk menganalisa perbedaan target domain dan source domain ini.

Skema analisis peribahasa ini akan mengacu pada model prisma yang dikembangkan oleh Geeraerts dalam buku Langlotz yang berjudul idiomatic creativity. Model tersebut menggambarkan akan adanya hubungan metafora antara makna sesungguhnya suatu peribahasa dengan bahasa yang digunakan dalam idiom tersebut (Langlotz, 2006: 109). Berikut adalah model prisma yang kemudian dikembangkan menjadi model prisma ganda karena akan digunakan untuk menganalisis dua $\gamma$

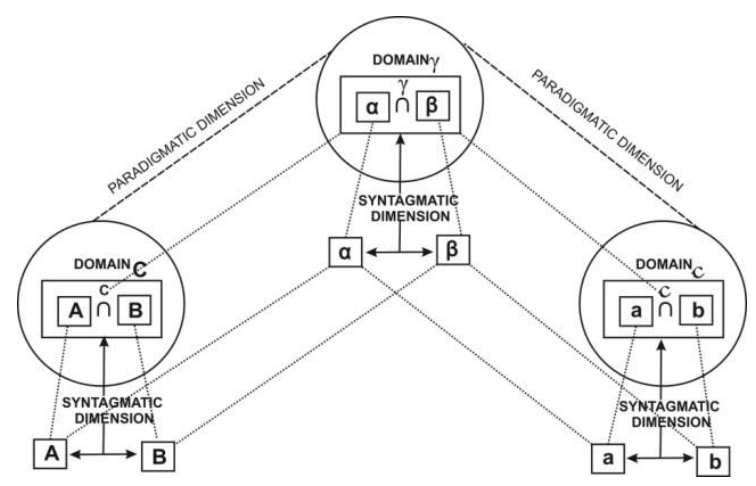

Gambar 3. Model Prisma Geeraerts dalam analisis Peribahasa ${ }^{1}$

Gambar di atas menggambarkan hubungan antara makna kalimat di dalam DOMAIN $\gamma$ berhubungan langsung dengan makna metaforis dalam DOMAN C dan DOMAIN C. Karena makna dalam DOMAIN C dan DOMAIN C bukanlah makna sesungguhnya maka yang ditunjuk oleh anak panah putus-putus tersebut bukanlah kotak yang membungkus A dan B maupun a dan b karena kotak tersebut adalah makna secara literal. Sehingga bisa dirumuskan bahwa peribahasa "still waters run deep" dan “air tenang menghanyutkan" memiliki makna yang sama yaitu orang yang pendiam biasanya banyak pengetahuan atau the person who is quiet ususally has a lot of knowledge.

Jika hal tersebut di masukkan ke dalam analisis model prisma milik Geeraerts maka konstituen $(\mathrm{A}=$ air tenang) dan $(\mathrm{B}=$ menghanyutkan) dengan konstituen ( $\mathrm{a}=$ still waters) dan ( $b=$ run deep) memiliki kesamaan makna dengan ( $\alpha=$ quiet person) dan ( $\beta=$ has much knowledge) (Langlotz, 2006: 110). Untuk mempersingkat analisis dengan model prisma tersebut agar lebih sederhana maka tabel 1 akan digunakan sebagai sarana menganalisis peribahasa dua bahasa yaitu bahasa Inggris dan bahasa Indonesia. Tabel 1 tersebut merupakan model penyederhanaan model prisma milik Geeraerts yang telah digambarkan di gambar 3 di atas.

\section{ANALISIS}

Analisis metafora, karena melibatkan dua peribahasa di dalamnya, akan menggunakan tabel untuk mempermudah dalam hal analisis dan mempermudah dalam hal penjelasan. Model tabel tersebut adalah sebagaimana berikut:

\begin{tabular}{|c|c|c|c|}
\hline \multicolumn{4}{|c|}{$\begin{array}{c}\text { Makna } \\
\text { Meaning }\end{array}$} \\
\hline \multicolumn{2}{|c|}{ X Peribahasa } & \multicolumn{2}{|c|}{ Y Proverb } \\
\hline $\begin{array}{c}\text { Target } \\
\text { domain A }\end{array}$ & $\begin{array}{c}\text { Source } \\
\text { Domain A }\end{array}$ & $\begin{array}{c}\text { Target } \\
\text { Domain B }\end{array}$ & $\begin{array}{c}\text { Source } \\
\text { Domain B }\end{array}$ \\
\hline & & & \\
\hline
\end{tabular}

Tabel 1. Bentuk penyederhanaan model prisma Geerarets pada gambar 1

\section{a. Air tenang menghanyutkan dalam dan still waters run deep}

Kedua peribahasa ini memiliki arti yang sama yang pertama air yang tenang menghanyutkan adalah orang yang pendiam biasanya banyak pengetahuannya, sedangkan yang kedua adalah a person who seems to be quiet or shy may surprise you by knowing a lot or having deep feeling. Analisis data tersebut 
untuk mengetahui target domain dan source domain akan diletakkan dalam tabel berikut:

\begin{tabular}{|c|c|c|c|}
\hline \multicolumn{4}{|c|}{$\begin{array}{c}\text { Orang yang pendiam biasanya memiliki banyak } \\
\text { pengetahuan } \\
\text { The person who isquiet ususally has a lot of } \\
\text { knowledge }\end{array}$} \\
\hline \multicolumn{2}{|c|}{$\begin{array}{c}\text { X Air tenang } \\
\text { menghanyutkan }\end{array}$} & \multicolumn{2}{|c|}{ Ystill waters run deep } \\
\hline $\begin{array}{c}\text { Target } \\
\text { domain } \\
\mathbf{A}^{\mathbf{1}}\end{array}$ & $\begin{array}{c}\text { Source } \\
\text { Domain } \\
\mathbf{A}^{\mathbf{2}}\end{array}$ & $\begin{array}{c}\text { Target } \\
\text { Domain } \\
\mathbf{B}^{1}\end{array}$ & $\begin{array}{c}\text { Source } \\
\text { Domain } \\
\mathbf{B}^{2}\end{array}$ \\
\hline $\begin{array}{c}\text { Orang } \\
\text { yang } \\
\text { pendiam }\end{array}$ & Air tenang & $\begin{array}{c}\text { Person } \\
\text { who is } \\
\text { quiet }\end{array}$ & $\begin{array}{c}\text { Still } \\
\text { waters }\end{array}$ \\
\hline $\begin{array}{c}\text { Target } \\
\text { domain } \\
\mathbf{C}^{1}\end{array}$ & $\begin{array}{c}\text { Source } \\
\text { Domain } \\
C^{2}\end{array}$ & $\begin{array}{c}\text { Target } \\
\text { Domain } \\
\mathbf{D}^{1}\end{array}$ & $\begin{array}{c}\text { Source } \\
\text { Domain } \\
\mathbf{D}^{2}\end{array}$ \\
\hline $\begin{array}{l}\text { Banyak } \\
\text { pengetahu } \\
\text { an }\end{array}$ & $\begin{array}{l}\text { menghany } \\
\text { utkan }\end{array}$ & $\begin{array}{c}\text { has a lot } \\
\text { of } \\
\text { knowledge }\end{array}$ & Run deep \\
\hline
\end{tabular}

Tabel 2. Perbandingan Peribahasa "Air tenang menghanyutkan" dan "still waters run deep"

Seperti yang dilihat dalam tabel bahwasannya pada $\mathrm{X}$ target $\operatorname{domain} \mathrm{A}$ dan pada target domain B sama-sama membandingkan antara orang yang pendiam dengan source domainA dan Bair yang tenang. Hal ini berarti kedua peribahasa tersebut memiliki thought domain yang sama bahwa air yang diam berarti tidak berisik atau alirannya tidak terdengar sebagaimana seseorang yang pendiam orang tersebut tidak akan banyak bicara dan tidak berisik.

Perbandingan yang kedua yaitu target domain $\mathrm{C}$ dan $\mathrm{D}$ memiliki kesamaan yaitu banyak pengetahuan atau mengetahui banyak hal, namun demikian untuk source domain $\mathrm{C}$ dan $\mathrm{D}$ berbeda karena yang $\mathrm{C}$ adalah menghanyutkan dan yang $\mathrm{D}$ adalah alirannya dalam. Maka thought domain antara peribahasa tersebut adalah bahwa bagi orang Indonesia bahwa orang yangbanyak pengetahuan maka akan membuat siapa saja terkesima sedangkan bagi masyarakat Inggris orang yang mengetahui banyak hal berarti dia memiliki pemahaman atau pikiran yang dalam.
Perbedaan dalam dua peribahasa ini padasource domain yang menyebabkan thought domain juga menjadi berbedadisebabkan oleh budaya yang berbeda antara masyarakat Indonesia dan Inggris. Masyarakat Indonesia mengatakan orang yang diam punya banyak pengetahuan dan jika berbicara akan membuat orang terkesima didasarkan pada budaya orang Indonesia yang senang berbincang-bincang bahkan sarana seperti BBM, Facebook, Twitter dan sebagainnya digunakan oleh orang Indonesia sebagai sarana untuk berbincang-bincang yang tak sedikit dari sosial media tersebut timbul banyak masalah. Hal ini berbeda dengan masyarakat Inggris. Masyarakat Inggris yang menganggap bahwa orang yang diam yang punya banyak pengetahuan memiliki pemahaman yang dalam dibangun melalui suatu kebiasaan dan budaya mereka yaitu membaca, karena kedalaman pemikiran seseorang hanya bisa dilihat dari cara orang tersebut menulis. Karena semakin dalam makna suatu analisis dalam penulisan maka bisa diketahui bahwa semakin dalam juga pemahamannya terhadap sesuatu hal.Selain itu budaya orang Inggris yang suka menganalisa sesuatu dan memperhatikan sesuatu sedangkan orang Indonesia lebih sering membicarakan dan memperbincangkan segala sesuatu.

\section{b. Bagai pinang dibelah dua dan like two peas in a pod}

Kedua peribahasa ini memiliki makna yang sama yaitu dua orang yang dianggap sama persis dan susah untuk membedakannya. Namun demikian meskipun keduanya memiliki makna yang sama terdapat beberapa perbedaan yang bisa dilihat pada tabel berikut: 


\begin{tabular}{|c|c|c|c|}
\hline \multicolumn{4}{|c|}{$\begin{array}{c}\text { Dua orang yang nampak sangat serupa } \\
\text { Two people look very similar }\end{array}$} \\
\hline \multicolumn{2}{|c|}{$\begin{array}{c}\text { Bagai pinang dibelah } \\
\text { dua }\end{array}$} & \multicolumn{2}{|c|}{ like two peas in a pod } \\
\hline $\begin{array}{c}\text { Target } \\
\text { domain } \\
\mathbf{A}^{1}\end{array}$ & $\begin{array}{c}\text { Source } \\
\text { Domain } \\
\mathbf{A}^{2}\end{array}$ & $\begin{array}{c}\text { Target } \\
\text { Domain } \\
\text { B }^{1} \\
\end{array}$ & $\begin{array}{c}\text { Source } \\
\text { Domain } \\
\mathbf{B}^{2} \\
\end{array}$ \\
\hline Orang & Pinang & Person & Peas \\
\hline $\begin{array}{l}\text { Target } \\
\text { domain } \\
\mathrm{C}^{1}\end{array}$ & $\begin{array}{l}\text { Source } \\
\text { Domain } \\
C^{2}\end{array}$ & $\begin{array}{l}\text { Target } \\
\text { Domain } \\
D^{1}\end{array}$ & $\begin{array}{l}\text { Source } \\
\text { Domain } \\
D^{2}\end{array}$ \\
\hline $\begin{array}{l}\text { Sama } \\
\text { persis }\end{array}$ & $\begin{array}{l}\text { Dibelah } \\
\text { dua }\end{array}$ & $\begin{array}{l}\text { Extremely } \\
\text { similar }\end{array}$ & $\begin{array}{l}\text { Two in a } \\
\text { pod }\end{array}$ \\
\hline
\end{tabular}

Tabel 3.Perbandingan peribahasa "bagai pinang dibelah dua" dan "like two peas in a pod"

Pada tabel terlihat bahwa perbedaan terletak pada source domain A dan B yaitu membandingkan antara manusia dengan pinang untuk $\mathrm{X}$ dan orang dengan kacang polong atau peas dalam Y. Perbedaan juga terdapat pada source domain C dan D yaitu mengibaratkan kesamaan dengan pembelahan atau pembagian dalam X sedangkan dalam Y mengibaratkan kesamaan dengan penempatan pada suatu tempat yang sama. Perbedaan yang sama-sama terjadi pada source domain A, B, C, dan D meskipun demikian tidak membedakan thought domainkarena antara masyarakat Indonesia dan Inggris sama-sama pernah melihat seseorang yang kembar. Perbedaaan di antara keduanya disebabkan oleh perbedaan referen yang dekat dengan mereka. Masyarakat Indonesia jaman dahulu menggunakan buah pinang untuk "susur" atau menguatkan gigi yang digunakan bersamaan dengan sirih, sedangkan pada masyarakat Inggris kacang polong digunakan sebagai sayur dalam menu makanan mereka.

\section{c. Bagai menegakkan benang basah dan \\ Looking for a needle in a haystack}

Kedua peribahasa ini memiliki arti yang sama yaitu melakukan hal yang sulit untuk dilakukan atau perbuatan yang sia-sia untuk dilakukan. Meskipun demikian kedua peribahasaa ini memiliki perbedaan pada source domain di keduanya yang dapat dilihat pada tabel berikut:

\begin{tabular}{|c|c|c|c|}
\hline \multicolumn{4}{|c|}{$\begin{array}{l}\text { Melakukan sesuatu hal yang sulit } \\
\text { Doing difficult things }\end{array}$} \\
\hline \multicolumn{2}{|c|}{$\begin{array}{c}\text { XBagai menegakkan } \\
\text { benang basah }\end{array}$} & \multicolumn{2}{|c|}{$\begin{array}{c}\text { YLooking for a needle } \\
\text { in a haystack }\end{array}$} \\
\hline $\begin{array}{c}\text { Target } \\
\text { domain } \\
\mathbf{A}^{1}\end{array}$ & $\begin{array}{c}\text { Source } \\
\text { Domain } \\
\mathbf{A}^{2}\end{array}$ & $\begin{array}{c}\text { Target } \\
\text { Domain } \\
\mathbf{B}^{1}\end{array}$ & $\begin{array}{c}\text { Source } \\
\text { Domain } \\
\mathbf{B}^{2}\end{array}$ \\
\hline $\begin{array}{c}\text { Melaku } \\
\text { kan } \\
\text { sesuatu }\end{array}$ & $\begin{array}{l}\text { Menegakk } \\
\text { an benang }\end{array}$ & $\begin{array}{c}\text { Doing } \\
\text { something }\end{array}$ & $\begin{array}{c}\text { Looking } \\
\text { for a } \\
\text { needle }\end{array}$ \\
\hline $\begin{array}{l}\text { Target } \\
\text { domain } \\
C^{1}\end{array}$ & $\begin{array}{l}\text { Source } \\
\text { Domain } \\
C^{2}\end{array}$ & $\begin{array}{l}\text { Target } \\
\text { Domain } \\
D^{1}\end{array}$ & $\begin{array}{l}\text { Source } \\
\text { Domain } \\
D^{2}\end{array}$ \\
\hline $\begin{array}{c}\text { Hal } \\
\text { yang } \\
\text { sulit }\end{array}$ & $\begin{array}{c}\text { dalam } \\
\text { keadaan } \\
\text { basah }\end{array}$ & Difficult & $\begin{array}{c}\text { in a } \\
\text { haystack }\end{array}$ \\
\hline
\end{tabular}

Tabel 4.Perbandingan peribahasa "bagai menegakkan benang basah"

Perbedaan pada $\mathrm{X}$ dan $\mathrm{Y}$ sama-sama terletak pada source domainbaik A, B, C, dan D. Pada X source domain $\mathrm{A}^{1}$ untuk target domain $\mathrm{A}^{1}$ melakukan sesuatu adalah menegakkan benang sedangkan pada $\mathrm{X}$ source domain $\mathrm{B}^{1}$ untuk target domain $\mathrm{B}^{1}$ melakukan sesuatu adalah mencari sebuah jarum. Perbedaan ini juga terdapat padasource domain $\mathrm{C}^{2}$ dan source domain $\mathrm{D}^{2}$ yaitu dalam keadaan basah dan dalam tumpukan jerami.Perbedaan dalam kedua metafora tersebut sebenarnya masih berhubungan satu sama lain, sebab jarum dan benang merupakan suatu alat yang digunakan untuk menjahit baju. Berarti masyarakat Inggris dan masyarakat Indonesia memiliki kesamaan yaitu keduanya sama-sama menggunakan alat berupa benang dan jarum untuk membuat pakaian.Perbedaan tersebut terletak pada budaya masyarakat Inggris dahulu yaitu ketika para lelaki berladang para wanita menyulam.Dalam menyulam yang senantiasa bergerak untuk membuat sulaman adalah jarum sedangkan jerami adalah komponen dari ladang yang digunakan untuk makanan ternak.Sedangkan di Indonesia pembuatan kain sarung di Sumatra 
misalnya peran jarum tidaklah begitu penting sebab di Sumatra memiliki alat pemintal tradisional.Sehingga perbedaan ini terletak pada pandangan penting atau tidaknya suatu benda bagi masyarakat tersebut.

\section{d. Sehari selembar benang, lama-lama} menjadi sehelai kain dan Rome wasn't built in a day.

Peribahasa Indonesia 'sehari selembar benang, lama-lama menjadi sehelai kain' dan peribahasa Inggris 'Rome wasn't built in a day' memiliki kesamaan makna yaitu pekerjaan yang sulit yang dikerjakan dengan penuh kesabaran, lama-lama akan berhasil juga untuk peribahasa Indonesia dan untuk peribahasa Inggris maknanya adalah a complicated a task will take a long time and needs patience.Meskipun sama maknanya namun keduanya memiliki hal-hal yang berbeda yang bisa dilihat dalam tabel berikut:

\begin{tabular}{|c|c|c|c|}
\hline \multicolumn{4}{|c|}{$\begin{array}{c}\text { Kesabaran membuahkan keberhasilan } \\
\text { Patience is the key of success }\end{array}$} \\
\hline $\begin{array}{c}\text { X Sehari selembar benang, } \\
\text { lama-lama menjadi sehelai } \\
\text { kain }\end{array}$ & $\begin{array}{c}\text { Y Rome wasn't } \\
\text { built in a day. }\end{array}$ \\
\hline $\begin{array}{c}\text { Target } \\
\text { domain A }\end{array}$ & $\begin{array}{c}\text { Source } \\
\text { Domain } \\
\mathbf{A}^{\mathbf{2}}\end{array}$ & $\begin{array}{c}\text { Target } \\
\text { Domain } \\
\mathbf{B}^{\mathbf{1}}\end{array}$ & $\begin{array}{c}\text { Source } \\
\text { Domain } \\
\mathbf{B}^{\mathbf{2}}\end{array}$ \\
\hline Kesabaran & $\begin{array}{c}\text { Sehari } \\
\text { selembar } \\
\text { benang }\end{array}$ & Patience & $\begin{array}{c}\text { Wasn't } \\
\text { built in a } \\
\text { day }\end{array}$ \\
\hline Target & $\begin{array}{c}\text { Source } \\
\text { Domain } \\
\mathbf{C}^{\mathbf{2}}\end{array}$ & $\begin{array}{c}\text { Target } \\
\text { Domain } \\
\mathbf{D}^{\mathbf{1}}\end{array}$ & $\begin{array}{c}\text { Source } \\
\text { Domain } \\
\mathbf{D}^{\mathbf{2}}\end{array}$ \\
\hline Keberhasilan & $\begin{array}{c}\text { Lama-lama } \\
\text { sehelai } \\
\text { kain }\end{array}$ & $\begin{array}{c}\text { Success } \\
\text { Rome }\end{array}$ & $\begin{array}{c} \\
\end{array}$ \\
\hline
\end{tabular}

Tabel 5.Kesabaran membuahkan keberhasilan

$$
\text { Perbedaan dalam menggambarkan }
$$

kesabaran atau patience terlihat jelas yaitu antara sehari selembar benang dan wasn't build a day (maksudnya membutuhkan proses yang tidak instan), sedangkan untuk keberhasilan orang Indonesia mengacu pada kain (hasil dari benang yang disusun) sedangkan orang Inggris mengacu pada Roma (hasil dari kota yang dibangun dengan kekuatan fisik dan pikiran). Perbedaan padaa source domain ini dipengaruhi oleh cara pandang masyarakat Indonesia dan Inggris mengenai proses yang dipengaruhi oleh budaya mereka. Budaya orang Indonesia yang suka bekerja dengan budaya orang Inggris yang suka membaca tergambar jelas pada peribahasa tersebut.Karena masyarakat Indonesia gemar bekerja maka salah satu hasil pekerjaan mereka berupa kain dijadikan sebagai sumber acuan metafora selain itu karena Indonesia juga merupakan jalur perdagangan antara banyak Negara di Jaman dahulu. Sedangkan masyarakat Inggris yang gemar membaca menjadikan Roma sebagai acuan karena mereka dekat dengan Roma dengan cara membaca dan berdasarkan sejarahpun Negara mereka termasuk dalam wilayah kekuasaan bangsa Romawi dan kemajuan teknologi mereka juga dipengaruhi oleh pemikiran-pemikiran bangsa Romawi.

\section{e. Nasi sudah menjadi bubur dan it's no use to cry over spilt milk}

Kedua peribahasa tersebut memiliki kesamaan makna yaitu tidak ada gunanya menyesali sesuatu yang sudah terjadi untuk peribahasa Indonesia sedangkan peribahasa Inggris bermakna it is pointless to repine when it is too late to remedy the misfortune. Namun demikian meskipun keduanya sama atau hampir sama dalam makna, ada perbedaan yang dapat dilihat pada tabel berikut:

\begin{tabular}{|c|c|c|c|}
\hline \multicolumn{4}{|c|}{$\begin{array}{l}\text { Menyesali sesuatu hal yang terlah terjadi } \\
\text { To repine something which has just happened }\end{array}$} \\
\hline \multicolumn{2}{|c|}{$\begin{array}{l}\text { X Nasi sudah menjadi } \\
\text { bubur }\end{array}$} & \multicolumn{2}{|c|}{$\begin{array}{c}\text { Y it's no use to cry over } \\
\text { spilt milk }\end{array}$} \\
\hline $\begin{array}{c}\text { Target } \\
\text { domain } \mathbf{A}^{1}\end{array}$ & $\begin{array}{c}\text { Source } \\
\text { Domain } \\
\mathbf{A}^{\mathbf{2}}\end{array}$ & $\begin{array}{c}\text { Target } \\
\text { Domain } B^{1}\end{array}$ & $\begin{array}{c}\text { Source } \\
\text { Domain } \\
\mathbf{B}^{2}\end{array}$ \\
\hline Menyesali & $\begin{array}{c}\text { Nasi } \\
\text { sudah } \\
\text { menjadi }\end{array}$ & To repine & $\begin{array}{c}\text { Milk } \\
\text { already }\end{array}$ \\
\hline
\end{tabular}




\begin{tabular}{|c|c|c|c|}
\hline $\begin{array}{l}\text { Target } \\
\text { domain } \mathbf{C}^{\mathbf{1}}\end{array}$ & $\begin{array}{l}\text { Source } \\
\text { Domain } \\
\mathbf{C}^{\mathbf{2}}\end{array}$ & $\begin{array}{l}\text { Target } \\
\text { Domain } \mathbf{D}^{\mathbf{1}}\end{array}$ & $\begin{array}{l}\text { Source } \\
\text { Domain } \\
\mathbf{D}^{\mathbf{2}}\end{array}$ \\
\hline $\begin{array}{c}\text { Sesuatu } \\
\text { yang sudah } \\
\text { terjadi }\end{array}$ & bubur & $\begin{array}{l}\text { Something } \\
\text { too late to } \\
\text { remedy }\end{array}$ & Spilt \\
\hline
\end{tabular}

Tabel 6.Menyesali sesuatu hal yang telah terjadi

Kedua peribahasa ini memiliki perbedaan pada source domain yang disebabkan oleh perbedaan hal yang dianggap penting oleh kedua masyarakat tersebut.Orang Indonesia yang memiliki lahan pertanian yang luas yang produk utama dan makanan pokoknya adalah nasi akan menganggap nasi adalah hal yang penting selain itu nasi juga dekat dengan masyarakat Indonesia dan bernilai ekonomi tinggi. Sedangkan pada masyarakat Inggris, susu adalah hal yang terpenting bagi mereka dengan nilai ekonomi yang tinggi dan dekat dengan mereka, karena sarapan mereka biasanya adalah roti dan susu.

\section{KESIMPULAN}

Penelitian kontrastif analisis sederhana ini menghasilkan suatu kesimpulan bahwa bahasa dipengaruhi oleh budaya yang muncul dari kegiatan sehari-hari, lingkungan sekitar, kebiasaan, dancara pandang. Penggunaan metafora peribahasa Inggris dan Indonesia terbukti menggunakaan referen/source domain yang dekat dengan mereka, yang penting bagi mereka, dan yang ada di sekitar mereka.Source domain yang dipengaruhi oleh faktor-faktor tersebut yang merupakan bagian dari budaya mempengaruhi penggunaan bahasa mereka.

\section{DAFTAR PUSTAKA}

Ahearn, L. M. (2012). Living Language: An Introduction to Linguistic Anthropology. India: Wiley-Blackwell.

Ahimsa-Putra, H. S. (2013).Strukturalisme LeviStrauss Mitos dan Karya Sastra. Yogyakarta: Kepel Press.
Chaniago, N. A. \& Pratama, B. (1998).Duaribu Tujuh Ratus Peribahasa Indonesia. Bandung: Pustaka Setia.

Duranti, A. (1997). Linguistic Anthropology. United Kingdom: Cambridge University Press.

Foley, W. A. 1997. Anthropological Linguistics: An Introduction. Great Britain: Blackwell Publishers.

Hadi, F.L., \& Nurhadi, D.N. (2018) Kajian Makna dan Nilai Budaya Peribahasa Jepang dan Indonesia yang Menggunakan Unsur Nama Binatang. GoKen, 6(2).

Hanindar, M. \& Andini, R. (2017).Analisis makna kotowaza yang terbentuk dari kata anjing serta padanannya dalam peribahasa Bahasa Indonesia.Japanology 5(2), 146-157.

Kovecses, Z. (2010). Metaphor:A Practical Introduction. New York: Oxford University Press.

Langlotz, A. (2006). Idiomatic Creativity: A Cognitive-linguistic Model of Idiomrepresentation and Idiom-variation in English. Amsterdam: John Benjamin Publishing Company.

Lyon, J. (1977). Semantics, Vol.1. Cambridge: Cambridge University Press.

Mirahyuni, N.K., \& Garnida, S.C. (2016).Nilai sikap bekerja dalam peribahasa Inggris sehubungan dengan kuda dan padanannya dalam bahasa Indonesia.Parafrase, 16 (1), 9-20.

Moleong, L.J. (2015). Metode Penelitian Kualitatif. Bandung: PT Remaja Rosda Karya.

Ogden, C. K \& Richards, I.A. (1923).The Meaning of Meaning. London: Routledge \& Keagen Paul.

Oxford. (2005). Oxford Advanced Learners' Dictionary. New York: Oxford University Press.

Poedjosoedarmo, S. (1983). "Penentuan Metode Penelitian”. Materi Kuliah 
Pascasarjana S-2 Linguistik 2007/2008.

Yogyakarta: Buku Hand Out.

Saussure, F. (1959).Course in General Linguistics.Trans. Wade Baskin. New York: Philosophical Library.

Tarigan, H.G. (1985). Pengajaran Gaya Bahasa. Bandung: Angkasa.

Wittgenstein. (1958). Philosophical Investigations. Great Britain: Basil Blackwell. 